\title{
Introduction: Markets and the New Welfare - Buying and Selling the Poor
}

\author{
Mark Considine and Siobhan O'Sullivan (University of Melbourne)
}

Accepted for publication in Social Policy and Administration (Wiley, 2014)

\section{Introduction}

With welfare reformers in almost every country experimenting with forms of privatization and what its advocates have called 'supervisory approaches to poverty' or 'a new behaviouralism', it is timely to present this special edition of Social Policy \& Administration. Dedicating a volume to the governance of quasi-markets in welfare services attests to the momentous nature of the radical re-design the welfare state has undergone over the past two decades. A similar reinvention has occurred across numerous policy fields and has affected most social services. Yet nowhere have the changes been more radical, and the results more pronounced, than in the realm of welfare-to- work, employment services privatization and jobseeker activation. All too often, social policy commentators are forced to lament that reforms were 'oversold' by policymakers, that things at the local level did not change all that much, or that major parts of the reform agenda of governments were effectively subverted by system inertia. Not in the case of employment services.

In 1992, Lawrence Mead argued that:

dependency politics is growing in importance not only in the United States, but in the West as a whole. In Europe, disputes over the social behavior of low income groups, often immigrant communities, have become more contentious than traditional conflicts between organized labour and capitalism. (Mead 1992: 3-4)

Deep concern for the large number of citizens who had become permanently dependent on unemployment benefits or related forms of social security, such as single parent payments or disability pensions, profoundly undermined whatever trust remained in large, bureaucratic, inflexible responses to poverty. By the 1990s, a spirited debate had surfaced on both the political left and the right, concerning the extent to which welfare entitlements had helped generate perverse effects, including the twin problems of state paternalism and dependency. 
No government responded to this challenge with greater enthusiasm than Tony Blair's New Labour. They took to public service reform with a zeal not seen since Gladstone, and with obvious gestures to the USA and the heyday of welfare reform under Roosevelt. Political devolution, strategic partnerships at local level, the various 'New Deals' for those on benefits and a new enthusiasm for engaging the private sector created a powerful momentum throughout the public sector. Blair and Bill Clinton had also forged a temporary consensus around new centre-left policies which aimed to 'square the circle' by adopting part of the right's critique of welfare and of the effect of passive welfare, but joining it to a better funded programme for increasing opportunity in both education and work.

These new principles of obligation and activation were hybridized and adapted to become a new regime of innovations across the Organisation for Economic Co-operation and Development (OECD), involving the strengthening of obligations for welfare recipients to earn their income support, the contracting-out of services and the reform of pension systems themselves to link them to workforce participation wherever possible.

Central to the response identified by many policymakers was the idea of New Public Management (NPM). According to the logic of NPM, traditional bureaucratic instruments based upon norms of standardized treatment and universal service are best replaced by outcome targets, quasi-market contracting and efforts to engage employers and other users in service delivery. Welfare and employment ministries in many OECD countries are now more likely to purchase services than to deliver them, more concerned with regulating contracts than managing public servants, and are increasingly concerned with managing an economy of incentives and opportunistic manoeuvres than with traditional forms of bureaucratic organization. Yet this spread of service out-sourcing only tells part of the contemporary welfare-to- work story. Described elsewhere as 'a decisive turn away from universal state services and standardized responses to social problems' (Considine 2001: 2), in order to appreciate the vastly different conception of jobseeker assistance today, compared to just 15 years ago, one must also take account of the impact of the new notion of 'activation' which began to influence policymakers in the 1990s and challenged thinking about welfare entitlement. 
California's Greater Avenues to Independence (GAIN) programme had been the largest programme of public assistance to the unemployed in the largest state in the USA. In 1994, the Manpower Demonstration Research Corporation, an influential non-profit evaluation agency, published the results of a three-year study of GAIN (Riccio et al. 1994). The evaluation drew 33,000 welfare recipients from the California welfare rolls and randomly assigned them to a study group and a control group. The conclusion was that the GAIN programme itself was successful and that Riverside was the most successful county. The measures of success were the gains in earnings for those who undertook the programme and the savings in welfare payments.

The Riverside model included a range of important differences compared to models trialed elsewhere. But despite multiple variables, the narrative which has developed around the Riverside case highlights a set of programme features which have now achieved the status of accepted wisdom among policymakers.

The first thing evaluators noted about Riverside was that its managers made less commitment to education and training and certainly less to longer-term educational deficits such as sending clients back to school to improve literacy and numeracy. Instead, the local strategy was to focus upon job search and immediate placement into available job vacancies. Even where the job was not what a client was looking for or very happy about, the philosophy was to take this job now and then apply for a better one from the stronger position of being employed. Efforts were also made to reduce the capacity of clients to defer their job search obligations because of part-time work, training or childcare responsibilities. In all these cases, the programme still required the client to participate in job search activities for up to 15 hours per week.

The staff in the programme closely monitored their clients to see that they were active and motivated to take jobs which were offered, and that they could resolve any issues which might make a successful job start more difficult. Having the right clothes, sorting out transportation and childcare, and having a clear understanding of the employers' expectations all played a part in this local strategy. The motivational message was strongly focused upon family values. 
This commitment to what would later be called a 'work first' approach was complemented by very active engagement with local employers. Specialist staff with marketing skills were hired to manage these critical relationships with local employers. The key to success was the job agency's ability to offer employers immediate service so they would come to rely upon them for filling temporary vacancies and managing the stress of sudden departures. The promise was to send a suitable applicant the same day the employer lodged the request, to follow-up the placement and to see that he or she was happy with the resulting placement. The manager of the Riverside programme also spent time promoting this pro-employer image in the local media and though existing employer networks. He further promoted a strong culture of performance among staff of the agency though his own motivational messaging and through the rapid dissemination of data about finding and filling vacancies.

While we might be unsure about what in particular made the Riverside model more successful than others, evidently it was an approach to employment assistance whose time had come. Critics of welfare were tired of hearing that clients lacked motivation, tended to avoid programmes if they could, and refused jobs if they felt something better would soon be available. Nor did the high cost of providing the educational skills missed at high school seem to these critics to be justified by the modest employment outcomes they appeared to produce. And most of all the growing coalition of welfare critics expressed dismay that local employers could have vacancies on their books, find it hard to get applicants or committed workers, while around the corner were welfare recipients sitting in an expensive public agency discussing other preferences they might have for work. Riverside became the poster child for programme design throughout the OECD. What was needed was a programme which was 'work first' but with tough requirements for participation and hard time limits for the receipt of benefits.

A new language of 'tough love' began to replace the liberal canon of entitlement. Where welfare programmes worked best they appeared to contain a good deal of pushing and prodding, and even stronger tactics to force claimants to take jobs. Plainly, the new science of welfare had become an administrative discipline, a science of governance in which those delivering programmes and those receiving them each had to be carefully activated though a new regime of exhortations and incentives, honed to achieve an explicit and exemplary change in behaviour. The tidal wave of administrative reform which would follow this shift in outlook by policymakers would carry as its leitmotif the charismatic figure of the 
Riverside manager, throwing the rule book of public assistance out the window with one hand, and pointing all clients to the first available local job with the other. The new administrative methodology aimed to be uncompromising; no excuses accepted, no exceptions allowed. With that the contemporary notion of 'activation' was born. It would forever change the case manager/jobseeker relationship. It would also have serious implications for the purchaser/provider relationship as governments sought ways to employ and then activate contracted agencies in order to eventually activate the end user.

As this special edition's title 'Markets and the New Welfare - Buying and Selling the Poor' suggests, the willingness of policymakers to take radical steps in relation to welfare-to-work may be indicative of the service users' status. In short, those in receipt of employment assistance are more often than not poor and disenfranchised. This is particularly so in the case of the long-term unemployed. Is the state emboldened when service recipients are predominantly marginalized? Or is the explanation for the depth of the reforms to be found in the relationship between welfare-to-work and its new economy? After all, innovative labour market management has material consequences for welfare recipients, employers and, perhaps most importantly, those private for-profit and not-for-profit agencies which have grown wealthy and politically powerful as a result of their new roles in delivering these public services.

While we can only speculate as to the reasons why welfare-to-work has been the locus of significant policy experimentation, what is not in doubt is the widespread nature of the phenomenon. In our own case, we find that Australia's approach to the public management of employment services has earned it an international reputation as a bold social policy reformer. Yet despite being the first country to introduce a fully privatized delivery model, steered by a rigorous contract management system, operated in a relatively benign labour market, the reform impetus has not achieved equilibrium, and the Australian government has become involved in continual restructuring of the system. It is for this reason that we refer to Australian employment services policy process as 'the reform that never ends' (Considine 2005). But while the Australian experience is one of bold employment service re-design, it is by no means a uniquely Australian story. As the diversity of scholars featured in this special edition demonstrates, the trajectory of reform is widespread, as is academic interest in the study, analysis and critique of the changes. 
This volume represents a new high-water mark in the field of employment services scholarship, yet participants draw on a much longer intellectual legacy. In particular, our contributing authors have all been influenced by research into NPM; social policy; public policy; activation; the welfare state; the third sector; 'flexsecurity'; mission drift; and quasimarkets. This special edition both confirms employment services delivery as a discrete field of research, and uses employment services as a case study to advance academic understanding in relation to a host of broader principles and concepts.

This special edition began as a roundtable hosted by the University of Melbourne in February 2013. The roundtable attracted papers from ten speakers spanning seven countries. The roundtable audience included employment services $\mathrm{PhD}$ students and our industry partners Jobs Australia (JA), the National Employment Services Association (NESA), and Westgate Community Initiatives Group (WCIG). All roundtable participants were invited to submit an article for consideration, but submissions were also accepted from those who were unable to make the long journey out to Australia.

The international perspective brought to bear on the topic 'Markets and the New Welfare Buying and Selling the Poor' by contributors to this volume is evidenced by the first two articles, which both take an international comparative approach. Katharina Zimmermann, Patrizia Aurich, Paolo R. Graziano and Vanesa Fuertes from Germany, Italy and the UK compare those three countries in relation to activation policy. In particular, the authors wish to identify the impact of 'marketized integrated activation policies' on different types of activation arrangements. In their own words:

marketization in the delivery of activation policies strongly emphasizes both individual responsibility and the need of a broader scope of actors to ensure targeted services. However, the way these activation principles are translated into practice strongly depends on their implementation at the local level, framed by the discretion local actors have with regard to the marketized services. (p. 128)

An exploration of activation via marketization is well facilitated by a com- parison of Germany, Italy and UK, because each country has undertaken marketization to different extents, via various levels of government and the use of a range of policy mechanisms. The 
authors find that the local context matters and that local discretion and the local policy history informs how activation policy is translated into actual service delivery practice.

Ludo Struyven from the Netherlands also adopts a comparative approach, examining the way in which quasi-markets developed in Australia, the Netherlands and Belgium. He asks:

What brought the two reform countries Australia and the Netherlands to make a similar choice for the restructuring of their PESs [public employment services]? How is it that Australia evolved after just a few years from an open to a closed market, whereas this did not happen in the Nether- lands? Why did Belgium (Flanders) not opt, in the period studied, for a new administrative structure with more scope for market competition, despite a far-reaching reform plan? (p. 150)

He argues that the move towards service privatization does not necessarily equate to system convergence and that ' $[\mathrm{t}]$ he three countries studied each follow their own path regarding the direction in which the system is evolving' (p. 163). Struyven carefully paints a complex picture and outlines the way in which various stakeholders influence system reform and rereform.

Many of the countries examined in the two comparative articles were used as case study jurisdictions by other contributing authors. Our own contribution, co-authored with Phuc Nguyen, is focused on Australia. In it we consider the relationship between NPM and mission drift, from a unique perspective. We track the evolution of an Australian third-sector employment services provider as it grew from a small kitchen table, church-based charity into a $\$ 15$ million enterprise. We complement that case study with data collected from chief executive officers and boards of other not-for-profit employment services providers in order to investigate the extent to which large-scale government contracting has altered board membership, process and ambition. We conclude that service privatization has changed the very nature of those who set the direction of third-sector service agencies. Those we interviewed emphasized the importance of being professional, business-like, and emulating the for-profit sector. This raises important questions about the broader impact of employment services privatization. Is it changing the very nature of the third sector? Are employment services the types of services not-for-profits should be delivering? And, lastly, if not-forprofits feel drive to emulate the for-profit sector, do they remain distinctive? If yes, in what ways? And does it matter? 
Rik van Berkel from Utrecht University's School of Governance focuses on the Dutch system and does so from a frontline perspective. He explores the dynamics between activation, 'risk selection', and the administration burden placed on client-facing staff. van Berkel's study suggests that the relationship between the three is not as straightforward as might be imagined. Using extensive interview data, van Berkel argues that on the question of risk selection, the process is complex and can happen at a range of points along the service continuum. He concludes that, "when studying processes of risk selection, research needs to analyze the entire service provision chain and to look at decisions taken by providers and purchasers throughout the service provision process' (p. 200).

Many social policy scholars, in particular employment services specialists, have been closely monitoring developments in the UK over the last three to five years. Two articles in this special edition are centred around the UK's bold reform agenda. Isabel Shutes and Rebecca Taylor from the London School of Economics and the University of Birmingham, respectively, concentrate their analysis on the impact of conditionality in funding which they argue, 'commodifies those out of work by attaching financial value to placing them in work' (p. 205). Within the context of the Work Programme, the authors find that conditionality in funding informs the types of agencies willing and able to deliver services; the 'mission' of those agencies which do deliver services; the capacity of agencies to specialize; and the willingness of providers to invest extensively in jobseekers. They also argue that it encourages 'creaming' and 'parking'. James Rees, Adam Whitworth and Elle Carter are also concerned with creaming and parking within the context of recent UK employment services reforms. In their article 'Support for All in the UK Work Programme? Differential Payments, Same Old Problem', they find that despite careful system design, aimed at minimizing adverse incentives, 'creaming and parking are widespread and systematically embedded within the Work Programme, and are driven by a combination of intense cost- pressures and extremely ambitious performance targets alongside overly diverse claimant groups and inadequately calibrated differentiated payment levels' (p. 221). The authors argue that funding differentiation between cohorts was the primary tool used by the policy architects to achieve their objective of 'differentiated universalism'. However, that design has not been effective, as evidenced by different placement rates between different classification groups. Rees, Whitworth and Carter conclude that 'the Work Programme at present seems . . to be 
reinforcing, exacerbating and making systemic the negative impacts of employment disadvantages' (p. 236).

Matthias Knuth provides a German perspective. He examines a special programme known as 'Perspective 50plus', implemented to assist jobseekers over the age of 50 receiving minimum income benefits. Knuth argues that the success associated with Perspective 50plus cannot be attributed to particular processes used to assist older jobseekers. Rather, positive outcomes are linked to innovative governance arrangements. For example, programme participation was voluntary at both the Jobcenter and client level. Moreover: targets were straightforward and clearly defined with regard to employment outcomes and their quality and duration ... sanctions in case of missing the targets were very soft, but underperforming did have consequences. All this created a sense of ownership different from standard operations compared to which the procedure was more bottom-up, more specifically targeted, and tied to locally specific action plans. (p. 253)

The Perspective 50plus case study is used by Knuth to further answer the more abstract question: 'how should hierarchical rules and market transactions be designed as to allow network relations to flourish and bear fruit? (p. 256).

Lastly, Avishai Benish makes a rather unique contribution by examining the purchaser/provider relationship in Israel. Much active labour market policy research is European or Australian focused. It is, therefore, particularly interesting to view the challenges presented by NPM from a relatively new jurisdictional perspective. Benish argues that:

the Israeli case, still understudied in activation scholarship, offers an excellent context for studying transformation in public accountability ... As a radical case of privatization, in which significant discretionary powers were devolved to for-profit street-level activation agencies (including the power to sanction participants from receiving income support payments), it may help us to understand and critically evaluate how accountability changes under privatized service delivery systems' ( $p$. 263)

Benish concludes that a distinction between public and private account- ability is a false dichotomy and, rather, there is a need to think in terms of a hybrid accountability model and 
that '[d]ecades of public sector welfare delivery, it seems, have created certain public expectations of how discretionary powers should be operated and how they should be accounted for, and these expectations remain when the functions are privatized' (p. 273). While each of the articles included in this special edition utilizes a national/ programme case study, and each considers employment services policy in general, and activation practices in particular, they are nonetheless unique and standalone contributions to the literature. It is our hope that, combined, they make a significant contribution to scholarship, and practice, in this important field. 


\section{References}

Considine, M. (2001), Enterprising States: The Public Management of Welfare to Work, Cambridge: Cambridge University Press.

Considine, M. (2005), The Reform that Never Ends: Quasi-Markets and Employment Services in Australia. In E. Sol and M. Westerveld (eds), Contractualism in Employment Services: A New Form of Welfare State Governance, The Hague: Kluwer Law International and Aspen Publishers.

Mead, L. (1992), The New Politics of Poverty: The Nonworking Poor in America, New York, NY: Harper Collins Publishers.

Riccio, J. A., Friedlander, D. and Freedman, S. (1994), GAIN: Benefits, Costs, and ThreeYear Impacts of a Welfare-to-Work Program, New York, NY: Manpower Demonstration Research Corporation. 